\title{
BIOTECNOLOGIA SEM FRONTEIRAS
}

GLAUCO ARBIX

\section{RESUMO}

A biotecnologia contemporâneaé um ponto de encontro onde distintos personagens conversam de modo inovador sobre os mais diversos temas. Ao manipular seres vivos para produzir bens e serviços, envolve tecnologias de diversos níveis, como os processos de fermentação e as técnicas de manipulação genética, e se apresenta como um paradigma técnico-científico essencialmente transdisciplinar.

PALAVRAS-CHAVE: biotecnologia; ciência; inovação; tecnologia.

\section{SUMMARY}

Contemporary biotechnology is a meeting point where distinct players exchange innovative experiences about a wide range of subjects. As it manipulates living beings to produce goods and services, it puts together technologies of different levels, as in fermentation processes and techniques of genetic manipulation. Nowadays, it presents itself as a techno-scientific paradigm which is essentially interdisciplinary.

KEYWORDS: biotechnology; science; innovation; technology.

[1] "To see a world in a grain of sand,

Num grão de areia ver um mundo Naflor silvestre a celeste amplidão Segura o infinito em sua mão Ea eternidade num segundo. and a heaven in a wild flower, hold William Blake infinity in the palm of your hand, and eternity in an hour". William Blake, "The Pickering Manuscript". Tradução: Alberto Marsicano.

A Física foi a rainha-mãe do século xx. Como ponto de partida, ampliou o governo humano sobre o mundo da natureza e da cultura, ainda que nem sempre com nobreza de resultados, como a chuva negra sobre Hiroshima e Nagasaki insiste em nos relembrar. Mais do que isso, porém, ao buscarmos as marcas distintivas do século passado invariavelmente nos deparamos com as tecnologias oriundas da física, que produziram automóveis e aviões, a TV, os computadores e a internet. 
Por toda a incerteza que envolve as jornadas rumo ao desconhecido, talvez seja um pouco cedo para afirmar que o século XXI terá na biotecnologia seu rebento mais bem-sucedido. Mas, pelo que já veio à luz, tudo indica que a promessa está feita.

Em várias economias e muitas empresas, a engenharia genética tende a tornar-se uma quase rotina. Em resposta às necessidades, ou emulada pela curiosidade humana, a pesquisa científica se defronta crescentemente com a natureza biológica de velhos e novos problemas, alguns tão candentes quanto gigantescos. Problemas que acompanham a marcha da humanidade há séculos, aparentemente já equacionados, como antigas (embora recorrentes) doenças ou o envelhecimento das populações; ou, então, desafios mais recentes, como as conseqüências das mudanças climáticas cujos mecanismos mais críticos têm sido estudados e associados ao dinâmico universo da biologia contemporânea.

Nem sempre, porém, os planejadores, autoridades públicas e mesmo a comunidade acadêmica estão preparados ou dispõem de instrumental adequado para reconhecer essas relações nada triviais e potencializar o conhecimento capaz de entender ou organizar essas novas realidades.

Não raramente, o universo é vasto demais para descansar na palma de nossas mãos, como no poema de Blake. Mas não há como esconder a inquietação que permeia qualquer debate sobre biotecnologia, dadas suas íntimas e perigosas relações com a vida, a saúde, o meio ambiente, o desenvolvimento, a prosperidade e o bem-estar das pessoas.

O dossiê preparado por Novos Estudos é exemplo desse mundo pleno de contrastes e desafios. Uma revolução inacabada está em curso. Nem sempre silenciosa. Irreverente às vezes. Insistentemente polêmica. E consistentemente atraente.A biotecnologia contemporânea é um ponto de encontro, onde distintos personagens conversam de modo inovador sobre os mais diversos temas. Com os olhos no futuro e energia suficiente para sacudir os parâmetros das ciências e disciplinas que ousam estudá-la, tanto por seus impactos sobre a ética e a moral, quanto por suas conseqüências no terreno da ciência, da sociologia ou da economia.

Ainda que em uma chave distinta das ciências da vida, o debate atual sobre o etanol ilustra tanto os dilemas da pesquisa em biotecnologia quanto revela os impasses do próprio país. De um modo especial, os biocombustíveis colocaram o Brasil diante de uma encruzilhada histórica, tornando mais dramático o esforço para encontrar ou construir - os caminhos para o seu desenvolvimento.

Dependendo das suas respostas e do comportamento de suas elites, incluída a acadêmica, o país poderá aproveitar (ou não) as novas oportunidades abertas pelos biocombustíveis para melhorar as condições econômicas, tecnológicas, sociais e culturais nas próximas décadas. Após 
décadas de preocupaçãoe e pesquisa,o Brasil surge não somente como um dos maiores produtores mundiais de etanol, mas também como um dos mais importantes laboratórios do mundo, dado o uso intensivo que faz há muito tempo de fontes de energia alternativas ao petróleo.

Além do preço do produto brasileiro ser o menor do mundo, o etanol derivado da cana-de-açúcartem a vantagem de geraroito vezes mais energia que a energia fóssil necessária para a sua produção, trazendo uma economia direta e relevante para os processos de emissão de carbono. No caso do milho, que representa a base da produção norte-americana (o grande concorrente do Brasil), essa relação nãoé maior do que 1,8 vez. Mais do que isso, a redução da emissão de carbono também se beneficia do etanol, pois para cada tonelada utilizada como combustível há uma economia de 2,3 toneladas de não-emissão de $\mathrm{CO}^{2}$ na atmosfera, ao mesmo tempo em que nenhum $\mathrm{SO}^{2}$ é emitido.

A competitividade brasileira está baseada na melhoria e na diversificação da cana (que permitiram a otimização da quantidade de sucrose produzida) e pelo sistema de produção simultânea tanto do açúcar quanto do etanol. As vantagens brasileiras foram obtidas com base em condições geográficas, ambientais e espaciais muito particulares, mas que exigiram muita pesquisa e tecnologia para levar o país à atual posição ímpar que ocupa no mercado internacional.

Como o etanol tem grandes chances de se tornar um substituto (ou complemento) significativo da gasolina - diante do aumento (e instabilidade) dos preços do petróleo assim como dos limites físicos das suas reservas -, o etanol brasileiro foi colocado na berlinda. Atualmente, o mercado mundial de gasolina consome quase 1,5 trilhão de litros por ano. Para atender uma demanda de 10\% desse mercado seria necessária uma produção dez vezes maior que a atual produção total brasileira.

Apenas por essa breve referência pode-se visualizar a enorme gama de oportunidades colocadas para o país, que tem nos biocombustíveis uma possibilidade concreta de alteraro seu posicionamento e inserção no mapa do comércio internacional.A condição para isso está concentrada em uma série de decisões capazes de orientar estrategicamente a manutenção (e mesmo o aprofundamento) da atual liderança do Brasil nesse setor. O que somente será alcançado à custa de muita pesquisa, pública e privada.

Atualmente, somente um terço da energia disponível na cana-deaçúcar(armazenada na sucrose)éefetivamente utilizada para a produção do açúcar e do etanol. Novas tecnologias, ainda não competitivas comercialmente (como as derivadas dos processos de hidrólise), permitirão a fabricação de etanol com baixo custo a partir da celulose. Se a pesquisa brasileira obtiver sucesso, o país terá condições de multiplicar a utilização de energia da cana e de dar, por isso mesmo, um salto gigantesco na sua relação com o restante do mundo. 
Será que decisões estratégicas apropriadas serão tomadas pelas autoridades? Será que a pesquisa brasileira estará à altura desse desafio? Terá as condições para tanto? E a biotecnologia, conseguirá assumir o papel de proa necessário para bem conduzir esse processo?

O exemplo do etanol apenas sugere novos caminhos para realocação dos investimentos, o reposicionamento das instituições e disposição dos pesquisadores. Coloca para toda a comunidade científica o debate sobre a construção de uma agenda integrada de pesquisa. Isso porque a biotecnologia não configura um setor com fronteiras claramente definidas. Diferentemente, mostra-se como um conglomerado de tecnologias que encontra aplicação em diferentes atividades produtivas.

Institucionalmente, as empresas de biotecnologia, em todo o mundo, expressam de modo cristalino essa diversidade e heterogeneidade. Em grande parte, nasceram da fusão de diferentes paradigmas tecnológicos, mas que muitas vezes se complementam, como a indústria de fármacos e a de sementes, por exemplo.

Ao manipular seres vivos para produzir bens e serviços, a biotecnologia envolve tecnologias de diversos níveis (como os processos de fermentação, utilizados há séculos, e as técnicas de manipulação genética, resultantes de avanços recentes no campo da biologia molecular) e se apresenta como um paradigma técnico-científico essencialmente transdisciplinar.

O salto da biotecnologia deu-se no início dos anos 1970, com o avanço da engenharia genética. Segundo Carvalho, "a biotecnologia moderna inicia o seu trabalho com seres vivos naturais para obter outros seres vivos não encontráveis na natureza, obtidos pela aplicação de técnicas não naturais de seleção, transformação genética e otimização fisiológica" ${ }^{2}$. A base científica para essa aventura foi o desenvolvimento da genética ao longo do século XX. Os trabalhos de Mendel em 1865 viabilizaram o grande salto da biotecnologia com a descoberta de Watson e Crick em 1953, com o modelo da dupla hélice do DNA. Esse avanço preparou o ambiente para uma verdadeira revolução iniciada na década de 1970, com as técnicas do DNA recombinante e da fusão celular³.

Para viabilizar seus avanços, a biotecnologia foi obrigada a estabelecer sinergias com várias disciplinas, dentre as quais as engenharias, principalmente a química, insubstituível no estudo de bioprocessos, como na indústria de fármacos, de alimentos e de petróleo. Em anos mais recentes, a biotecnologia também encontrou suporte na engenharia da computação - bioinformática - para desenvolver programas embebidos de base matemática, capazes de dar conta dos desafios do seqüenciamento genético, que tentam descrever a relação entre genes e proteínas (proteoma), chave para a compreensão dos processos vitais 4 .
[2] Carvalho, A.P. "Biotecnologia". In: Schwartzman, S. Ciência e Tecnologia no Brasil: a capacitação brasileira para a pesquisa tecnológica e cientifica. Rio de Janeiro: Ed. Fundação Getúlio Vargas, 1996.

[3] Ver: Idem; Patricio, I. E. M. S. Biotecnologia emercados:perspectivas para o caso brasileiro. Rio de Janeiro: UFRJ, 1993 (dissertação de mestrado).

[4] Ver: Paugh, J.e Lafrance, J. C. The U.S. Biotechnology Industry. U. S. Department of Commerce - Office of Technology Policy, julho de 1997. 
[5] Dal Poz, M. E. Da dupla à tripla hélice: o Projeto Genoma Xylella (dissertação de mestrado). DPCT-I,Unicamp, Campinas, 2000.

[6] Ver: Higgins, M. Career Imprinting: The Case of the Baxter Boys and Biotechnology. Book ms., Harvard Business School, 2004; Porter, K., Whittington K. B. e Powell, W. "The Institutional Embeddedness of HighTech Regions: Relational Foundations of the Boston Biotechnology Community", Stanford University, mimeo, 2006; Shane, S. Academic Entrepreneurship: University Spinoffs and Wealth Creation. Cheltenham, UK: Edward Elgar, 2004.
Essas características brevemente descritas estamparam na biotecnologia o timbre de uma ciência de encruzilhada, uma vez que suas atividades mais relevantes exigem o concurso simultâneo de várias disciplinas e a colaboração de especialistas de áreas diversas.

Esse processo ocorre dentro e fora dos laboratórios, nas empresas e consórcios que se dedicam aos temas relacionados à saúde, agricultura, meio ambiente e indústria. Em todas essas áreas, as empresas se pautam pela diversidade, interdisciplinaridade e por uma grande dependência das pesquisas em Ciência e Tecnologia (C\&T).

Dal Poz salientou como os clusters de biotecnologia nos Estados Unidos e na União Européia, apesar das diferenças, apresentam uma configuração em rede para dar conta da malha de interdependências necessária para o sucesso das empresas, tanto nas áreas de fronteira (genômica e proteômica), quanto nas intensivas em tecnologia 5 .

Estudos recentes ${ }^{6}$ sugerem fortemente que a pesquisa em biotecnologia exige um ambiente especial para florescer, a começar de uma capacitação sistemática de recursos humanos e disponibilidade de financiamento de custo reduzido. Mais do que isso, porém, a possibilidade de inovar nessa área está diretamente relacionada ao grau de internacionalização das fontes de pesquisa. Isso significa que, além de produzir e reproduzir bons profissionais, é fundamental que existam laços fortes entre os pesquisadores e os centros de pesquisa, tanto no plano nacional quanto no internacional.

Nesse sentido, a construção de ambientes favoráveis ao desenvolvimento da biotecnologia não obedece aos parâmetros do curto prazo nem resiste às simplificações da demanda tradicional por mais verbas, ainda que, evidentemente, na realidade brasileira, estas sejam necessárias.

A complexidade organizacional das redes de biotecnologia e a busca de sua internacionalização surgem como um grande desafio para os formuladores de políticas de Ciência, Tecnologia e Inovação, uma vez que no Brasil a pesquisa acadêmica sobre esses ambientes ainda é muito incipiente. A experiência internacional e nacional tem mostrado, porém, que os casos de êxito permitem a difusão generalizada e a potencialização da pesquisa em um ritmo muito superior ao tradicional, o que confere aos processos de produção de conhecimento novo uma dinâmica até há poucos anos inimaginável.

As redes de biotecnologia mais consistentes se estruturam como corpos de natureza quase-pública, ou semipública. O alto custo, risco e a incerteza que envolvem os empreendimentos exigem constantemente o concurso de várias instituições, públicas e privadas, que agem cooperativamente de modo a obter complementaridade nas diferentes fases das investigação. Nem o mercado nem o Estado, isoladamente, dão conta dessa realidade. O modo de operar da biotecnologia, a competência exigida para dar forma e manter os ambientes propícios ao 
seu desenvolvimento não podem prescindir dos recursos materiais, humanos e institucionais do setor público, nem do investimento e empreendedorismo do setor privado.

Nos Estados Unidos existem empresas dedicadas à biotecnologia (EDBs) com até 2000 funcionários7. Intensivas em pesquisa, aglomeram-seem clusters e investem bilhões de dólares por ano em pesquisas de longa maturação e alto custo e risco. Em grande parte, essas empresas se originaram a partir de spin offs de universidades. Até hoje, cerca de $80 \%$ das EDBs americanas estão instaladas em parques tecnológicos ligados a centros universitários de pesquisa, e foram praticamente financiadas por um mercado de capital de risco, que no Brasil ainda engatinha ${ }^{8}$.

Mesmo com muitas dificuldades, a produção brasileira é relevante, reconhecida mundialmente e crescente. Em dezembro de 2004, a revista Nature Biotechnology publicou um suplemento com os resultados do survey internacional "Health Biotechnology Innovation in Developing Countries". O item dedicado ao Brasil recebeu o sugestivo título de "The scientific muscle of Brazil's health biotechnology". Coordenada pelo Programa Canadense em Genômica e Saúde Global, do Joint Centre for Bioethics da Universidade de Toronto, a pesquisa avaliou o setor de biotecnologia em saúde de sete países em desenvolvimento. O Brasil, na época, apareceu bem na foto. Contribuiu para isso o sucesso da produção de insulina humana recombinante, processo desenvolvido e patenteado pela Universidade Federal de Minas Gerais (UFMG) e pela empresa Biobrás. Na mesma chave, a revista destacou a importância crescente da fabricação de vacinas e o seqüenciamento da Xylella fastidiosa, patrocinado pela Fapesp. Os pontos de referência na área da saúde apontaram para a Fundação Oswaldo Cruz (Fiocruz), no Rio de Janeiro, e os Institutos Butantan e Ludwig de Pesquisa sobre o Câncer, ambos em São Paulo.É sempre bom lembrar que o número de publicações de cientistas brasileiros sobre biotecnologia em saúde cresce ininterruptamente desde o final dos anos 1990.

O debate e o estudo sobre as especificidades da produção científica em biotecnologia podem impulsionar ainda mais essa área do conhecimento. Se os textos aqui publicados contribuírem para despertar a curiosidade e o élan científico de nossos leitores, a iniciativa já terá valido a pena.

GLAUCO ARBIX é professor no Departamento de Sociologia da FFLCH-USP.
[7] Ver:Da Silveira,J.M.,Dal Poz,E.e Melo, M. "Overview Biotecnologia". Mimeo, 2003.
Recebido para publicação em 7 de julho de 2007.

\section{NOVOS ESTUDOS}

CEBRAP

78 , julho 2007

pp. 5-10 